\title{
Mineral Content Analysis of Polyherbal Energy Bar Using X-Ray Fluorescence Technique
}

\author{
Mansi Chitkara', Rajneet Kohli², Inderjeet Singh Sandhu', Didar Singh², Gagandeep Kaur ${ }^{3}$, Rakesh Kumar \\ Sindhu ${ }^{3^{*}}$
}

\section{Mansi Chitkara', Rajneet Kohli², Inderjeet Singh Sandhu', Didar Singh', Gagandeep Kaur ${ }^{3}$, Rakesh Kumar Sindhu ${ }^{3 *}$}

\begin{abstract}
'Nanomaterials Research Laboratory, Department of Applied Sciences, Chitkara University, Rajpura, Patiala - 140401, Punjab, INDIA. ${ }^{2}$ Chitkara College of Hotel Management and Catering, Chitkara University, Rajpura, Patiala-140401, Punjab, INDIA.

${ }^{3}$ Department of Pharmacognosy and Natural Products, Chitkara College of Pharmacy, Chitkara University, Rajpura, Patiala-140401, Punjab, INDIA.

Correspondence

Dr. Rakesh Kumar Sindhu
\end{abstract}

Department of Pharmacognosy and Natural Products, Chitkara College of Pharmacy, Chitkara University, Rajpura, Patiala - 140401, Punjab, INDIA.

Phone no : +91 01762507084

E-mail: rakeshsindhu16@gmail.com

\section{History}

- Submission Date: 07-06-2018;

- Review completed: 07-07-2018.

- Accepted Date: 01-11-2018

DOI : 10.5530/pj.2019.1.10

Article Available online

http://www.phcogj.com/v11/i1

\section{Copyright}

(c) 2019 Phcog.Net. This is an openaccess article distributed under the terms of the Creative Commons Attribution 4.0 International license.

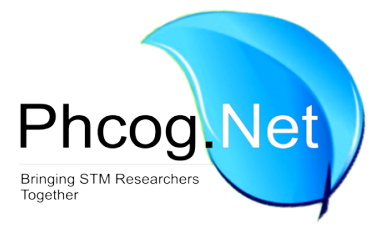

\begin{abstract}
Aim: The objective of the present study was to develop a novel energy bar which is nutritious and cost effective. Materials and Methods: The components used for the novel energy bar were banana, orange, peanuts, raisins, cocoa butter, stevia leaves and oats. Mineral contents of energy bar were analysed by XRF technique. Results: The mineral contents were present in comparable amount. Major elements viz. K 17.15\%, P 4.57\%, Mg 1.43\%, Ca 0.93\%, Na 0.66\%, $\mathrm{S} 0.54 \%$, Fe $0.15 \%$, Zn $0.05 \%$ and $\mathrm{Cu} 0.02 \%$ were present in energy bar. Conclusion: Minerals are good for overall growth of body. The energy bar also contains no preservatives, binding agents and sugar free. So, the energy bar is major source of energy and minerals for all age group individuals.
\end{abstract}

Key words: Energy bar, Mineral content, Polyherbal, Calcium, Iron, Potassium.

\section{INTRODUCTION}

Consumers demand and desire the health foods, which are portable, convenient and proportioned as well. Often, many options aren't available that are minimally processed, rich in nutrients and tastes good. ${ }^{1}$ The food bars are snacks of good sensory and nutritional characteristics due to their high carbohydrates, proteins, lipids and minerals contents. ${ }^{2}$ One of the major challenges is to provide consumers with healthy ready to eat foods. Often, many options aren't available that are minimally processed, rich in nutrients and tastes good. Energy bars, a food product that fits these criteria, continue to increase in sales according to the AC Nielsen Market Track. ${ }^{3}$ The energy bar consists of banana, peanuts, raisins, oats, orange juice, stevia leaves, cocoa butter and chocolate. Banana scientifically known as Musa paradisiaca belonging to family Musaceae. It is major source of proteins and energy. It has also powerful antioxidant and antidabetic potential. ${ }^{4}$ Peanuts are a favourite food, whether eaten alone as a snack food or mixed into candy and cookies etc. Peanuts are good sources of monounsaturated fats, vitamin E, niacin and $\mathrm{B}_{6}{ }^{5,6}$ Oats are rich source of dietary fibers, beta glucans and dietary fibres which are helps in reduction of glucose level in diabetic patients and also acts as hypolepidemic agent. ${ }^{7,8}$

The dark chocolate is great source of energy and it is an anti-oxidant, good for the heart, also as memory enhancer used. ${ }^{9}$ Cocoa butter contains saturated fat and low amounts of caffeine and theobromine. It also contains lipids dissolving antioxidants such as $\alpha$ and $\beta$, $\gamma$-tocopherol which helps in its storage by increasing its therapeutic properties. ${ }^{10}$ Minerals are very good source of energy for overall health. Theygenerally help in maintenance of muscles functioning, acid base balance and nerve stimulations. ${ }^{11}$

The objective of the present study was to prepare a healthy and nutritional energy bar by using different natural ingredients. Also, to check the mineral contents present in the energy bar using X- Ray Fluorescence (XRF) method.

\section{X-ray Fluorescence}

$\mathrm{XRF}$ is the emission of $\mathrm{x}$-rays from a material that has been excited by bombarding with high energy $\mathrm{x}$-rays or gamma rays. This technology provides one of the simplest, most accurate and most cost-effective analytical methods for the investigation of the chemical composition of many types of materials, particularly in the determination of metals, building materials, glass and ceramics and also for research in geochemistry and forensic science. It is nondestructive and reliable, requires no, or very little, sample preparation and is suitable for solid, liquid and powdered samples. ${ }^{12}$ It can be used for wide range of elements and provide detection limits at the sub-ppm level. ${ }^{13}$

\section{MATERIALS AND METHODS}

\section{Raw Materials}

Raw materials like ripe banana, oranges, raisins, oats, cocoa butter, dried stevia leaves, dark 
compound chocolate for final coating were purchased from the local market.

\section{Method of Preparation}

1. Ripe banana pureed in a mixer grinder added with the juice of two oranges approximately. Roasted peanuts which have their skin removed are ground in a mixer to a powdered form all these are mixed with cocoa butter and powdered stevia leaves.

2. All ingredients are cooked together on low heat until the juice evaporates and becomes a homogeneous paste on low simmered heat for $15 \mathrm{~min}$ approximately for a batch of approximately $400 \mathrm{gm}$ puree of ripe banana.

3. On cooling the mixture we added the oats and raisins and refrigerated the mixture for half an hour, so that we may hands mold them into shape or bars.

4. This is later dipped in tempered dark chocolate of $31^{\circ} \mathrm{C}$ to form the outer coating and thereby completing the bar.

\section{Tempering of chocolate}

1. First pieces of chocolate are broken put in a heavy bottom pan in a double boiler and allowed to melt.

2. The temperature of chocolate has to be regulated by a thermometer and bought up to approximately 42 to $45^{\circ} \mathrm{C}$.

3. This process is repeated at least two times, with alternation of cooling and heating, the chocolate is cooled till $30^{\circ} \mathrm{C}$. This temperature change is done to bring out a shine and texture to the chocolate and repeated till the desired sheen is acquired. The chocolate being melted at controlled temperatures is what tempering is all about.

\section{Mineral Content Determination}

\section{Sample preparation}

The $100 \mathrm{gm}$ of energy bar sample was weighed using weighing machine. The quantity was poured into crucibles then it was placed in the muffle furnace for combustion to a temperature of $500-600^{\circ} \mathrm{C}$. The ash obtained after combustion allowed cooling in the muffle furnace for $24-30 \mathrm{~h}$ to room temperature and with the use of forceps and spatula the content of the crucibles for each sample was transferred into a pan for a Re-weighed.

\section{Method of XRF Analysis}

The method of XRF analysis involves keeping the geometry of the tubesample-detector assembly constant; the sample was prepared as a flat disc, typically of diameter $28 \mathrm{~mm}$ and thickness $1 \mathrm{~mm}$. Samples were located at a standardized, small distance from the tube window. Because the X-ray intensity follows an inverse-square law, the tolerance for this placement and for the flatness of the surface must be very tight in order to maintain a repeatable X-ray flux. Ashes were machined to shape and finely ground and pressed into a tablet. A further reason for obtaining a flat and representative sample surface was that the secondary X-rays from lighter elements often only emit from the top few micrometers of the sample..$^{14,15}$

\section{RESULTS AND DISCUSSION}

White milky ash was obtained after combustion of energy bar in furnace. The various elements were detected by XRF method. The major elements which were detected sodium, potassium, calcium, iron, phosphorus and magnesium etc.

Potassium $(\mathrm{K})$ is also a vital mineral for maintaining fluid and electrolyte balance in the body. Potassium in association with sodium ions, potassium plays an important role in the nerve functions and also for muscle

\begin{tabular}{cccc|}
\multicolumn{5}{c}{ Table 1: Mineral composition of Polyherbal energy bar. } \\
\hline Sr. No. & Elements & Intensity & Percentage \\
\hline 1 & $\mathrm{~K}$ & $424.4 \mathrm{KCps}$ & $17.15 \%$ \\
2 & $\mathrm{P}$ & $100.9 \mathrm{KCps}$ & $4.57 \%$ \\
3 & $\mathrm{Na}$ & $3.2 \mathrm{KCps}$ & $0.66 \%$ \\
4 & $\mathrm{Mg}$ & $20.1 \mathrm{KCps}$ & $1.43 \%$ \\
5 & $\mathrm{Fe}$ & $15.3 \mathrm{KCps}$ & $0.15 \%$ \\
6 & $\mathrm{Cu}$ & $4.0 \mathrm{KCps}$ & $0.02 \%$ \\
7 & $\mathrm{Mn}$ & $3.2 \mathrm{KCps}$ & $0.05 \%$ \\
8 & $\mathrm{Ca}$ & $16.3 \mathrm{KCps}$ & $0.93 \%$ \\
9 & $\mathrm{Zn}$ & $14.3 \mathrm{KCps}$ & $0.05 \%$ \\
10 & $\mathrm{~S}$ & $18.9 \mathrm{KCps}$ & $0.54 \%$ \\
\hline
\end{tabular}

Kilocounts per second (KCps)

growth. K $17.15 \%$ was present in novel polyherbal energy bar as shown in Table 1. Magnesium $(\mathrm{Mg})$ is an essential mineral for the human body and it helps in strengthen immune system and maintain normal nerves and muscles function. Magnesium also helps in reduction of blood pressure and blood glucose level. ${ }^{16}$

$\mathrm{Mg}$ 1.43\% was present in novel polyherbal energy bar as shown in Table 1. Calcium $(\mathrm{Ca})$ is a mineral that is mainly associated with strengthen of bones, teeth and gums. Ca plays an important role in the normal functioning of the mechanism of blood coagulation, for normal muscle functioning. Ca $0.93 \%$ was present in novel polyherbal energy bar as shown in Table 1. Phosphorous (P) helps to synthesize protein for the growth, maintenance and repair of cells and tissues. P 4.15\% was present in novel polyherbal energy bar as shown in Table 1 . Zinc $(\mathrm{Zn})$ is an essential mineral for normal growth and development during pregnancy, childhood, adolescence and proteins synthesis in body. The insufficiency of zinc may lead to diarrhoea, stunted growth, impotence, hair loss and skin diseases and weak immunity. Zn $0.05 \%$ was present in novel polyherbal energy bar as shown in Table 1. Iron ( $\mathrm{Fe}$ ) is an essential metal ion that is involved in oxygen transport and helps regulate cell growth and differentiation. It is known that the deficiency of iron leads to anaemia which is prevalent in many parts of the world. ${ }^{17} \mathrm{Fe} 0.15 \%$ was present in novel polyherbal energy bar as shown in Table 1 . Copper $(\mathrm{Cu})$ plays a role in proteins synthesis in our body such as collagen and hemoglobin, which transport oxygen. ${ }^{18} \mathrm{Cu} 0.02 \%$ was present in novel polyherbal energy bar as shown in Table 1.

\section{CONCLUSION}

On the basis of results obtained it could be concluded that newly developed energy bar was recorded remarkable number of mineral contents. Minerals are very essential for overall mental and physical growth. Novel energy bar is good source of mineral content and thus individual feeding this energy bar will not be mineral deficient. It is beneficial for diabetic patients because there were stevia leaves used as a natural sweetener and no chemical preservatives added. The product is also gluten free so it is safe for celiac patients. This energy bar is very cost effective and it could be used as a substitute for expensive commercial formula.

\section{ACKNOWLEDGEMENT}

The authors are grateful to Dr. Madhu Chitkara, Vice Chancellor, Chitkara University, Rajpura, Patiala, India and Dr. Ashok Chitkara, Chancellor, Chitkara University, Rajpura, Patiala, Punjab, India for support and institutional facilities. 


\section{CONFLICT OF INTEREST}

The authors declare no conflict of interest.

\section{ABBREVIATIONS}

XRF: X- Ray Fluorescence; K: Potassium; Ca: Calcium; Mg: Magnesium; P: Phosphorus; Fe: Iron; Cu: Copper; KCps: Kilocounts per second.

\section{REFERENCES}

1. Mridula D, Singh KK, Barnwal P. Development of omega -3 rich energy bar with flaxseed. J Food Science Tech. 2013;50(5):950-7.

2. Ooamah BD. Flaxseed as a functional food source. J Sci Food Agric. 2001;81(9):889-94

3. BIS IS: 6273 Part I and Part II Guide for sensory evaluation of foods. Indian Standard Institution, Manak Bhawan, New Delhi. 1971.

4. Famakin O, Fatoyinbo A, ljarotimi OS, Badejo AA, Fagbemi TN. Assessment of nutritional quality, glycaemic index, antidiabetic and sensory properties of plantain (Musa paradisiaca)-based functional dough meals. J Food Sci Technol. 2016;53(11):3865-75.

5. Mahmoud AH, EIAnany AM. Nutritional and sensory evaluation of a complementary food formulated from rice, faba beans, sweet potato flour and peanut oil. Food Nutr Bull. 2014;35(4):403-13.

6. Reyna VN, Bermudez PV, Mengual ME, et al. Oat-derived $\beta$-glucan significantly improves HDLC and diminishes LDLC and non-HDL cholesterol in overweight individuals with mild hypercholesterolemia. Am J Therap. 2007;14(2):203-12.

7. Butt MS, Nadeem MT, Khan MKI, Shabir R. Oat: unique among the cereals. European J Nutrition. 2008;47(2):68-79.
8. Settaluri VS, Kandala CVK, Puppala1 N, Sundaram J. Peanuts and Their Nutritional Aspects-A Review. Food and Nutrition Sciences. 2012;3(12):1644-50.

9. Fernell M, Swinton C, Lukowiak K. Epicatechin a component of dark chocolate, enhances memory formation if applied during the memory consolidation period. Commun Integr Biol. 2016;9(4):816-23.

10. Naik B, Kumar V. Cocoa Butter and Its Alternatives: A Reveiw. J Bior Eng and Tech. 2014;1:7-17.

11. Odom TC, Udensi EA, Iweh MO. Nutritional evaluation of unripe Carica papaya, unripe banana, Mucuna cochi weaning food formulation. Eur J Bio Med Sci Res. 2013;1:6-15.

12. John A, Alexanda S, Larry A. Approaching a universal sample preparation method for XRF analysis of powder materials. International center for Diffraction Data 2001, Advances in X-Ray Anal. 2001;44:368-70.

13. Jenkins R. X - Ray Fluorescence Spectrometry. Wiley Interscience, New York. 1999;5-7.

14. Loupilov A, Sokolov A, Gostilo V. X-Ray Peltier Cooled detectors for X-Ray Fluorescence analysis. Radiat Phys Chem. 2001;61(3-6):463-4.

15. Omatola KM, Onojah $A D$. Elemental analysis of rice husk ash using $X$ - ray fluorescence technique. Int J Phy Sci. 2009;4(4):189-93.

16. Larsson SC, Wolk A. More Magnesium-Rich Food for Less Diabetes. Journal of Internal Medicine. 2007;262(2):208-14.

17. Miret S, Simpson RJ, McKie AT. Physiology and Molecular Biology of Dietary Iron Absorption. Annual Review of Nutrition. 2003;23(1):283-301.

18. Anonymous. Institute of Medicine, Food and Nutrition Board. Dietary Reference. Intakes for Vitamin A, Vitamin K, Arsenic, Boron, Chromium, Copper, lodine, Iron, Manganese, Mo-lybdenum, Nickel, Silicon, Vanadium and Zinc. 2001.

\section{GRAPHICAL ABSTRACT}

\begin{tabular}{|c|c|c|c|}
\hline \multicolumn{4}{|c|}{ Miner al composition of Polyherbal energy bar } \\
\hline Sr. No. & $\begin{array}{l}\text { E lements } \\
\mathrm{K}\end{array}$ & $\begin{array}{l}\text { Intensity } \\
424.4 \mathrm{KCps}\end{array}$ & $\begin{array}{l}\text { Percentage } \\
17.15 \%\end{array}$ \\
\hline 2. & $\mathrm{P}$ & $100.9 \mathrm{KCps}$ & $4.57 \%$ \\
\hline 3. & $\mathrm{Na}$ & $3.2 \mathrm{KCps}$ & $0.66 \%$ \\
\hline 4. & $\mathrm{Mg}$ & $20.1 \mathrm{KCps}$ & $1.43 \%$ \\
\hline 5. & $\mathrm{Fe}$ & $15.3 \mathrm{KCps}$ & $0.15 \%$ \\
\hline 6. & $\mathrm{Cu}$ & $4.0 \mathrm{KCps}$ & $0.02 \%$ \\
\hline 7. & $\mathrm{Mn}$ & $3.2 \mathrm{KCps}$ & $0.05 \%$ \\
\hline 8. & $\mathrm{Ca}$ & $16.3 \mathrm{KCps}$ & $0.93 \%$ \\
\hline 9. & $\mathrm{Zn}$ & $14.3 \mathrm{KCps}$ & $0.05 \%$ \\
\hline 10. & $\mathrm{~s}$ & $18.9 \mathrm{KCps}$ & $0.54 \%$ \\
\hline
\end{tabular}

Kilocounts per second ( $\mathrm{KCps}$ )

\section{SUMMARY}

- The present study provides evidence that polyherbal energy bar contains various types of minerals and proteins which are helpful in growth of body. This energy bar contains all natural ingredients and no added synthetic chemical preservative and binder in formulation.

\section{ABOUT AUTHORS}

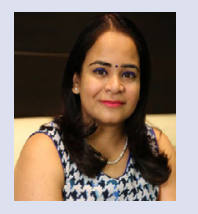

Dr. Mansi Chitkara: Professor and Head, Nanomaterials Research Laboratory, Chitkara University, Rajpura, Punjab. She obtained her Ph.D. Degree in Mechanical Engineering from Punjab Technical University and the title of her Ph.D. thesis was Synthesis and Characterization of semiconductor nano-materials. She did her Master of Engineering in Industrial Materials \& Metallurgy from Punjab Engineering College, Chandigarh. Her research area includes Nano-materials, Nano-Herbal materials synthesis and characterization for Pharmaceutical and Medical applications. She has published more than 35 research papers in reputed International Journals, International/National Conferences. She is currently guiding Ph.D., M.Tech., M.Pharm. students in the field of Nano-science and Technology. For further research details follow her research gate Professor and Head, Nanomaterials Research Laboratory, Chitkara University, Rajpura, Punjab. She obtained her Ph.D. Degree in Mechanical Engineering from Punjab Technical University and the title of her Ph.D. thesis was Synthesis and Characterization of semiconductor nano-materials. She did her Master of Engineering in Industrial Materials \& Metallurgy from Punjab Engineering College, Chandigarh. Her research area includes Nano-materials, NanoHerbal materials synthesis and characterization for Pharmaceutical and Medical applications. She has published more than 35 research papers in reputed International Journals, International/National Conferences. She is currently guiding Ph.D., M.Tech., M.Pharm. students in the field of Nano-science and Technology. For further research details follow her research gate

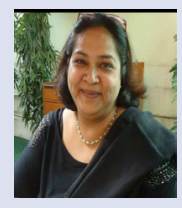

Ms. Rajnit Kohli: Principal, IHM, Bathinda, Punjab, affiliated to NCHMCT under ministry of tourism. She had 27 years of experience in the hospitality Sector and her expertise in food and berevages formulation and development. 


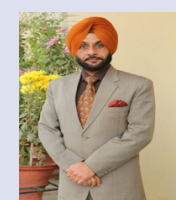

Dr. Inderjeet Singh Sandhu obtained his Ph.D. Degree in Solid State Physics from Kurukshetra University, Kurukshetra by doing research work on "Study of Diffusion in Solids \& Intermetallic Compounds". He did his M.Sc. in Physics (specialization in Electronics) from Kurukshetra University, Kurukshetra. He is having 20 years experience in Teaching, Research and Academic Administration. He has guided 04 Ph.D. thesis and is guiding 04 Ph.D. students at present. His research areas include Nanomaterials, Nanoelectronics, and Nanoelectrodynamics. He has published several papers in high impact factor journals, attended and presented papers in national and international conferences. He has published several book chapters/research articles in international publications, like: Springer, CRC Press, Taylor \& Francis Group. For further research details follow his research gate link: https://www.researchgate.net/profile/Inderjeet_Sandhu

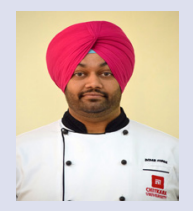

Chef Didar Singh: Assistant Professor in Institute of Hotel Management, Chitkara university, Rajpura, Punjab. India He has obtained M.Sc. (Hotel Management, Catering Technology and Tourism) and has a Advanced diploma in Hotel Management from George Brown College, Toronto, Canada. He carries an overall experience of 9 years both in industry and academics. He specializes and is an in-charge of Bakery and Confectionery operations, Chitkara School of Hospitality, Chitkara University.

Gagandeep Kaur: She did her B. Pharmacy from Chitkara College of Pharmacy, Chitkara University, Punjab, India

Dr. Rakesh K. Sindhu: Associate Professor in Department of Pharmacognosy and Natural Products, Chitkara College of Pharmacy, Chitkara University, Rajpura, Punjab, India. He is doctorate in pharmaceutical sciences from Chitkara University, Punjab. He did his M Pharmacy (Pharmacognosy) from Guru Jambheshawar University of Science and Technology, Hisar, Haryana. He is involved in research regarding standardization, Phytochemical and Pharmacological Evaluation of herbal drugs/ products. Formulation development and standardization of herbal products He had published more than 25 research papers in reputed journals and presented papers in 8 international and 30 national conferences. He is actively involved in reviewing research papers of well repute journals and member and serving as editorial broad member for national and international journals. During 11 year of my experience in academics. He was member of organizing committee for 7 International conferences. He has filled 5 patents and published 1 book chapters.

Cite this article: Chitkara M, Kohli R, Sandhu IS, Singh D, Kaur G, Sindhu RK. Mineral Content Analysis of Polyherbal Energy Bar Using X-Ray Fluroscence Technique. Pharmacog J. 2019;11(1):53-6. 